\title{
THE RISKS TO HUMAN HEALTH AND ENVIRONMENTAL IMPACTS FROM COMMUNITY E-WASTE SEPARATION
}

\author{
Pornnapa SUTAWONG ${ }^{1}$, Det WATTANACHAIYINGCHAROEN ${ }^{2}$, Norihiro ITSUBO ${ }^{3}$, \\ Kasemson SUVANNARAT
}

DOI: 10.21163/GT_2020.151.33

\begin{abstract}
:
The environmental and health impacts on the case study 'Khok Saat community' of the toxic substances and gases produced in this e-waste processing, are obvious and measurable. Two scenarios were developed. A life cycle assessment approach was carried out focusing on the end-of life phase. The ReCiPe Endpoint (H) v.1.10 method was used as the main LCIA method in this study. The result showed that all of impacts in scenario 2 were higher than scenario 1. For 'Human Health (HH)' impact, Human Toxicity indicator was highest and 'Resource Availability (RA)' impact, Fossil Depletion indicator was highest in both scenarios. For 'Ecosystem Diversity (ED)' impact, Terrestrial Ecotoxicity indicator was highest in scenario 1 and Climate Change Ecosystem was highest in scenario 2. The knowledge and understandings gained in this research can be used to inform policy makers and regulating bodies on the need for, and benefits of, a proper and enforceable legal and regulatory framework for the e-waste recycling industry.
\end{abstract}

Key-words: E-waste, Life cycle assessment (LCA), Global warming potential (GWP), Human health and environmental impact, Co-benefit

\section{INTRODUCTION}

Cheap labor cost and a weak legislation system are two important factors of the existence, and increase in the number of informal or community e-waste separation operations in developing countries (Awasthi et al., 2016; Sadhan et al., 2016). Approximately $80 \%$ of e-waste from developed countries such as the United States, Western Europe, China, Japan, and Australia, amongst others, is transported to many developing countries such as India, Ghana and Nigeria and also China for material separating and recycling by using primitive techniques, without appropriate facilities to safeguard environmental and human (Aimin, et. al., 2011). The e-waste import not only offer the business, but also satisfy the demand for cheap second-hand electrical and electronic equipment which is a source of livelihood for the urban and rural pool (Sadhan et al., 2016) and strongly related to financial motivation (Vi \& Matthew, 2014). Hazardous substances, improper disposal methods, and inefficient recycling methods have created an environmental problems of near disastrous proportions, especially for local communities close to informal and uncontrolled e-waste recycling sites, with the generated pollutants having a significant impact on human health by skin absorption, inhalation, and digestion

\footnotetext{
${ }^{12}$ Naresuan University, Faculty of Agriculture, Natural Resource and Environment, Thailand, Pornnapa.nu@gmail.com;

${ }^{2}$ Naresuan University, Faculty of Agriculture, Natural Resource and Environment, Thailand, Detw@nu.ac.th;

${ }^{3}$ Tokyo City University, Faculty of Environment and Information, Japan, Itsubo.norihiro@ gmail.com;

${ }^{4}$ Naresuan University, Faculty of Agriculture, Natural Resource and Environment, Thailand, Ksbangkokthai@gmail.com;
} 
(Awasthi et al., 2016). Also, poorly waste management causes a high impact on health, environment, and economy (Tantanee et al., 2019). Hazardous substances such as Pb in CRT monitors, Freon gas from air conditioners and refrigerators are also dangerous (John-Michael \& Yaakov, 2015). The seriously polluting metals are $\mathrm{Ni}, \mathrm{Cu}, \mathrm{Pb}$, and $\mathrm{Cd}$. Especially, $\mathrm{Pb}$ and $\mathrm{Cu}$ are the most hazardous metals demanding effective protection for the workers, but which is usually missing (Takashi et al., 2012). There are many obstacles such as the lack of environmental awareness, workers' unwillingness to be regulated or inability to be regulated because of fear of losing their job, income or profits. Activists at the local level are often fearful of becoming socially marginalized if they try to take action because of the dependence of the community on the profits and incomes generated. Therefore, informal and unregulated e-waste recycling is firmly established in these communities and cannot be phased out (Sabrina \& Dabo, 2016). Both recognizes the efficiency of the informal recycling industry and to strengthen work-place health and safety requirements for the recyclers, by moving away from end-of-pipe technologies and move towards Design for Environment (DfE) thinking (Sabrina \& Dabo, 2016). Eco-design with producer responsibility is increasing recovery of value from waste, creating a demand for recycled materials, and decreasing the potential harmful effects of waste (Wonorahardjo, 2019). Building informal e-waste recycling strengths while operating in cleaner ways and still retaining livelihoods is essential for reducing the ill effects of current practices (John-Michael \& Yaakov, 2015). Futhermore, law enforcement, and the e-waste recycling system are the key successful to reduce the impacts of mobile phone recycling (Vi \& Matthew, 2014) and the key factors in reducing the overall impacts are optimizing energy consumption efficiency, reducing waste effluent, using proper waste treatment method, and clearly defining the duties of all stakeholders (Jinglan et al, 2015). To reach the sustainable development goals, changing the environmental resource consumption, behavior routines and governance mode are nescessary (Kabisch, 2019). Furthermore, awareness of natural resources sustainability is very important to be motivated to increase stakeholder control over the application of good governance and must be intergrated in school currucula (Wonorahardjo, 2019; Dwianika et al., 2020).

The impact of heavy metal contamination on human health takes a long time to become apparent. Environmental measurement studies are necessarily longitudinal and conducted over a long period of time, and are therefore expensive. The life cycle assessment method (LCA) is apply to assess the environmental and health impacts in e-waste recycling activities and e-waste management (Jinglan et al., 2015; Souza, et al., 2016). Therefore, an appropriate method for measuring the current and future environmental and health impacts is the LCA which measures such parameters as global warming potential (GWP), human health $(\mathrm{HH})$, ecosystem diversity (ED), and resource availability (RA) impacts. This study utilized the LCA method, and calculations and simulations were done using the SimaPro 8.0.3 software computer program.

\section{STUDY AREA}

This study focused on the community recycling processing sites which are located in many regions throughout Thailand. There are four big e-waste recycling comunities (Fig. 1). Khok Saat community was selected because there are several community recycling sites owned by local people who have operated their business for a long time. This study site utilizes both residential and separate recycling areas. There is located in the Khong Chai District of Kalasin province in the northern east of Thailand. 
From prior studies, it was known that the concentrations of mercury, lead, cadmium, copper and nickel in surface water and rice paddy adjacent to the dumping area were lower than the regulatory threshold but higher than other residential area (Saetung, 2009). The concentation of heavy metals ( $\mathrm{Co}=37 \mathrm{mg} / \mathrm{kg}, \mathrm{Cu}=6,416 \mathrm{mg} / \mathrm{kg}, \mathrm{Pb}=2,527 \mathrm{mg} / \mathrm{kg}$, $\mathrm{Zn}=2,253 \mathrm{mg} / \mathrm{kg})$ in top soil $(0-5 \mathrm{~cm})$ in dumping site area were higher than the agriculural area standard. The tests on soils collected from informal recycling activities area, which showed levels of copper, lead and zinc contaminations higher than other residential areas (DDC, 2011). At the commencement of the current study, data was collected by taking 207 blood samples from local people working in informal recycling households, people not associated with a recycling household and children from the school in Khok Saat subdistrict area. Tests on these blood samples confirmed the prior information when they showed that 21 children and 3 adults had high levels of lead in their blood samples contained. One child's blood sample did show higher lead concentrations than the standard allowable value $(\mathrm{Pb}$ concentration $>60 \mu \mathrm{g} / \mathrm{dl}$; (DDC, 2011). There is also every reason to believe that the levels of these heavy metals will rise in the future with continuing e-waste recycling activities, unless action is taken to regulate the industry, and introduce safe practices.

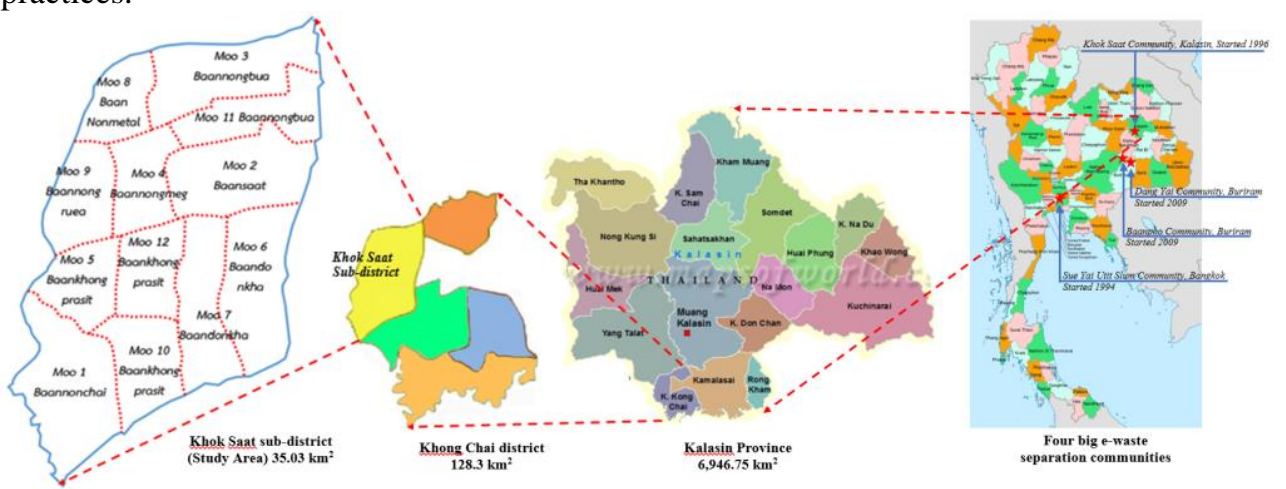

Fig. 1. The administrative boundaries of Khok Saat sub-district

\section{MATERIAL AND METHOD}

The environmental performance of the ewaste separation community at Khok Saat community was assessed by conducting a life cycle assessment according to the international standard of ISO 14044 series (ISO 14044: 2006). The life cycle assess framework is shown in Fig. 2.

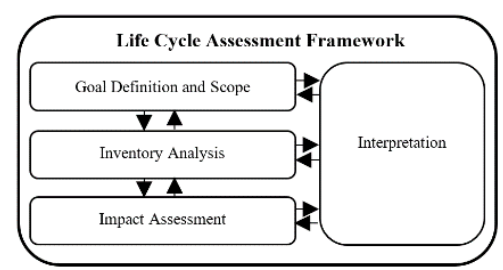

Fig. 2 Phase of LCA (Source: ISO 1997)

\subsection{Goal and Scope}

The objectives of this study were to assess (i) the environment and health impacts from e-waste separation activities, and (ii) the co-benefit from e-waste separation activities. For System boundaries step, the major activities in the Khok Saat community were taken into account when using the life cycle assessment (LCA) method as the analysis tool (Fig. 3). Two scenarios were conducted. Scenario 1 included six main separation sub-processes (A1, A2, B, C, D, and E) in the Khok Saat community area. The dumping site area was also 
included in this scenario as (F). Eight semi-products were produced that cannot be used as raw material directly. They are sent to a smelter or refinery, or other processing factories. Therefore, scenario 2 was constructed with the six main separation sub-processes in scenario 1 plus seven other sub-processes $(\mathrm{G}, \mathrm{H}, \mathrm{I}, \mathrm{J}, \mathrm{K}, \mathrm{L}$, and $\mathrm{M}$ ) being taken into account.

The assumption in this study was that all of the e-waste was disassembled in separation sub-processes (Sub-Processes A-E). Some recyclable materials were sent to a recycling factory, a refinery, or a smelter in Bangkok (Sub-Processes H-M) while only electronic scrap material was sent for precious metal extraction in Japan (Sub-Process G). Materials that cannot be recycled were disposed in the dumping site area $(\mathrm{F})$. The data for separation processes, Sub-process A-F, in Khok Saat area were surveyed by the authors. However, data for the recycling by smelter and refining processes were provided by an independent company in a SimaPro 8.03 dataset.

\subsection{Life cycle inventory}

Based on both the investigation in the field and a literature review, an e-waste flow diagram illustrating the two scenarios and the four types of e-waste was developed (Fig. 3). By reusing this waste material to produce new material, the consumption of energy and virgin material can be reduced. Our calculations of the dimensions of this benefit are shown in

Fig. 5, and discussed further below.

The life cycle inventory analyzed in this research, the raw materials were four types of obsolete equipment. Two energy sources, electricity and diesel oil, were used. The assumption in this study was that the residual, unrecyclable wastes were created from subprocesses $\mathrm{A} 2, \mathrm{~B}, \mathrm{C}$, and $\mathrm{D}$, in the case of scenario 1 . The main residual wastes were $\mathrm{CFC}$, oil, and urethane from refrigerator waste separation, burned PVC from electric wire burning, and panel glass, funnels, guns, and yokes from CRT monitor disassembly. These processes all created emissions into the air and/or contamination of the soil. In scenario 2, wastes were created from $\mathrm{G}, \mathrm{H}, \mathrm{I}, \mathrm{J}, \mathrm{K}, \mathrm{L}$, and M sub-processes.

\subsection{Life Cycle Impact Assessment}

Life Cycle Impact assessment (LCIA) was developed and used to evaluate and interpret the environmental impacts of a production system by assigning quantifiable measurement to specific dimensions. The "ReciPe Endpoint $(\mathrm{H})$ v.1.10" method was used as the main LCIA method in this study. ReciPe 2008 comprises two sets of impact categories with associated sets of characterization factors. Eighteen input categories are addressed at the midpoint level. At the endpoint level, most of these midpoint categories are further converted and aggregated into the following three endpoint categories; damage to human health $(\mathrm{HH})$, damage to ecosystem diversity (ED), and damage to resource availability (RA). (ReciPe 2008, update February 2013).

\subsection{Limitation of the Study}

The environmental impact results in this study were underestimated due to the limited fundamental data. First, the impact from toxic substances composition in e-waste that can be emitted from manual dismantling processes (sub-process A2 and B) is irrelevant, and have no effect on workers' health and do not contaminate the soil and surface water. As such, they were not taken into account in this study. Second, the amount of waste in scenario 1 was not included due to its being low quality and/or broken recyclable material that cannot be recycled. Therefore, the percentage of recyclable material is an overestimation. 


\section{RESULT AND DISCUSSION}

This field study considered the real production percentage of the Khok Saat community. Two scenarios, shown in Fig. 3 were classified. The functional unit was the ewaste separation system of Khok Saat community. One tonne of e-waste was considered as the recycling sample. It consisted of four types of obsolete electronic equipment; mobile phones $(2.44 \%)$, desktop computers with cathode ray tube type $(22.11 \%)$, television sets with cathode ray tube type $(39.09 \%)$, and refrigerators $(36.36 \%)$. The percentage of the total weight of each type of material was showed in Fig. 3. The impacts in terms of 'Global Warming Potential (GWP)', 'Human Health (HH)', 'Ecosystem Diversity (ED)', and 'Resource Availability (RA)' were analyzed.

\subsection{Global Warming Potential (GWP)}

The result of 'GWP' of the semi-products and finished products from 1 tonne of ewaste are presented in a comparative manner in Fig. 4. In both scenarios, the fraction of plastic material was higher than the other products, meaning that the GWP of the plastic material was highest. Almost plastic scraps are plastic cabinet and case from CCRT, TCRT, $\mathrm{RF}$, and MP. There were $38.53 \mathrm{kgs} \mathrm{CO} 2 \mathrm{eq}$ for 'Mixed Plastic material' and 'Crushed plastic material' and $781.06 \mathrm{kgs}$ CO2eq for Plastic (M). The 'GWP' of 1 kilogram of each material; 'Crushed Plastic Material' was highest $(0.1887 \mathrm{kgs} \mathrm{CO} 2 \mathrm{eq} / \mathrm{kg}$ of product) in the case of semi-product but 'Silver (Ag)' was highest ( $5.2733 \mathrm{kgs} \mathrm{CO} 2 \mathrm{eq} / \mathrm{kg}$ of product) in the case of finished product. Total GWP of eight of the semi-products was $87 \mathrm{kgs}$ CO2eq/tonne of e-waste (1.175 kgs CO2eq/kg of products). Total GWP of the 13 finished product was $1,153 \mathrm{kgs} \mathrm{CO} 2 \mathrm{eq} /$ tonne of e-waste $(48.2838 \mathrm{kgs} \mathrm{CO} 2 \mathrm{eq} / \mathrm{kg}$ of products).

\subsection{Damage to Human Health (HH), Ecosystem Diversity (ED), and Resource Availability (RA)}

The results of 'HH', 'ED', 'RA' of the semi-products and finished products from 1 tonne of e-waste are presented in a comparative manner in Fig. 4 that showed the results from Scenario 1 and 2 from 1 tonne of input e-waste. Unsuitable treatment at 'Dumping site area (F)' and improper recycling process of 'Electric Wire Separation Househouse (C)' by open burning produced toxic emission to air $(\mathrm{Cl}, \mathrm{Pb}$, Carbon, $\mathrm{PM}, \mathrm{PCDD} / \mathrm{PCDA})$ and soil $(\mathrm{Cl}, \mathrm{Pb}, \mathrm{Cu}, \mathrm{Sb})$. There were high potential impacts to human and ecosystem. However, in this study the ferrous metal material product was highest by weight (42.14\% of products) so it's the main impacts for 'HH' and 'ED'. From Fig. 4, 'HH' in terms of 'Human Toxicity' was highest (9.65E-04 DALY). The production process of 'Ferrous metal material' produced the main fraction in 'Human Toxicity' (4.02E-04 DALY). The total 'HH' impact was 1.22E-03 DALY/tonne of e-waste (1.69E-05 DALY/kg of product). 'ED' in terms of 'Terrestrial Ecotoxicity' was highest (4.77E-06 Species.yr). The production process of 'Ferrous metal material' produced the main fraction of 'Terrestial Ectoxicity' (1.99E-06 species.yr). The total 'ED' impact was 6.09E-06 species.yr/tonne of e-waste (8.46E-08 species.yr/tonne of product). 'RA' in terms of 'Fossil Depletion' was highest (USD\$3.8415).

The results from Scenario 2 where eight semi-products from Scenario 1 were sent for processing at a smelter, refinery or recycling factory. Fuel (Diesel, Gasoline) from transpotation process and electricity from pulify processes were the major impacts for ' $\mathrm{HH}$ ', 'ED', 'RA'. From Fig. 4, 'HH' in terms of 'Human Toxicity' was highest (1.67E-03 DALY). The production process of 'Plastic (M)' was the main fraction in 'Human Toxicity' (8.92E-04 DALY). The total 'HH' impact was 3.52E-03 DALY/tonne of e-waste (1.51E-03 DALY/kg 
of product). 'ED' in terms of 'Climate Change Ecosystem' was highest (9.14E-06 Species.yr). The production process of 'Plastic (M)'was the main fraction in 'Climate Change Ecosystem' (6.19E-06 species.yr). The total 'ED' impact was 1.50E-05 species.yr/tonne of e-waste (6.12E-07 species.yr/tonne of product). 'RA' in terms of 'Fossil Depletion' was highest (US\$10.69). The production process of 'Steel an Iron (H)' was the main fraction (US\$4.04). The total 'RA' was US\$11.69 per tonne of e-waste (USD $\$ 0.8483$ per tonne of product). The human health impact 'HH' was highest impact in every products. Ferrous metal and plastic product were the major source.

\subsection{Co-benefit for recycling as compared to the virgin product}

Materials which were recovered from recycling e-waste can be used as feedstock in further processes in order to minimize utilization of virgin material, and which also reduces energy consumption. At the same time, environmental degradation can be reduced. In this study, the impact in the term of 'GWP', 'HH', 'ED', and 'RA' for finished products were compared with virgin production. The health and environmental impacts of different types of virgin materials were obtained from the dataset in SimaPro 8.0.3. Twelve finishedproducts from 7 processes were compared (Fig. 5). For 'GWP', the recovery of lead $(\mathrm{Pb})$ from used mobile phone battery and rubber from CRT monitor was not relevant. The other finished-products were. In all cases, the 'GWP', 'HH', 'ED', and 'RA' impacts of Au (G) was the highest, followed by $\mathrm{Pd}(\mathrm{G})$ an $\mathrm{Ag}(\mathrm{G})$.

From our study 'Human health (HH)' impact in the term of 'Human toxicity' was highest in both scenarios. The results were the same impact from mobile phone Printed Circuit boards (PCBs) recycling in Malaysia (Vi \& Matthew, 2014). The environmental impact study of e-waste recycling in China was different, ecosystem diversity was highest. For e-waste treatment with end-life disposal (ET-D) scenario ecosystem diversity impact in marine ecotoxicity indicator is highest but terrestrial ecotocixity indicator is highest for ewaste treatment without end-life disposal (ET-ND) (Jinglan et al., 2015). For the ReCiPe midpoint assessment method, the impacts from plastic recycle product were lower than virgin plastic product. The impact from virgin plastic are higher 1.43 times in GWP, 1.20 times in HH, 1.04 times in ED and 18.51 times in RA. The results are in line with another study on plastics recycling, which showed that the virgin plastic production has a higher impact than recycling plastic production by 6-10 times (Patrick \& Roland, 2015).

\section{CONCLUSIONS}

Two scenarios of e-waste recycling were investigated in this study. Scenario 1 investigated six separation activities in the Khok Saat community area. This represented the first level of the e-waste treatment system in that area. Scenario 2 included the first, second, and third levels of the e-waste treatment system in the area. The knowledge and understandings gained in this research can be used to inform policy makers and regulating bodies on the need for, and benefits of, a proper and enforceable legal and regulatory framework for the e-waste recycling industry, which we have identified as being both a potentially profitable activity for small businesses, but also being highly damaging to the environment and to public health, unless properly controlled and regulated. Law enforcement, and the e-waste recycling system are the key successful to reduce the impacts of e-waste recycling and the key factors in reducing the overall impacts are optimizing energy consumption efficiency, reducing waste effluent, using proper waste treatment method, and clearly defining the duties of all stakeholders. 


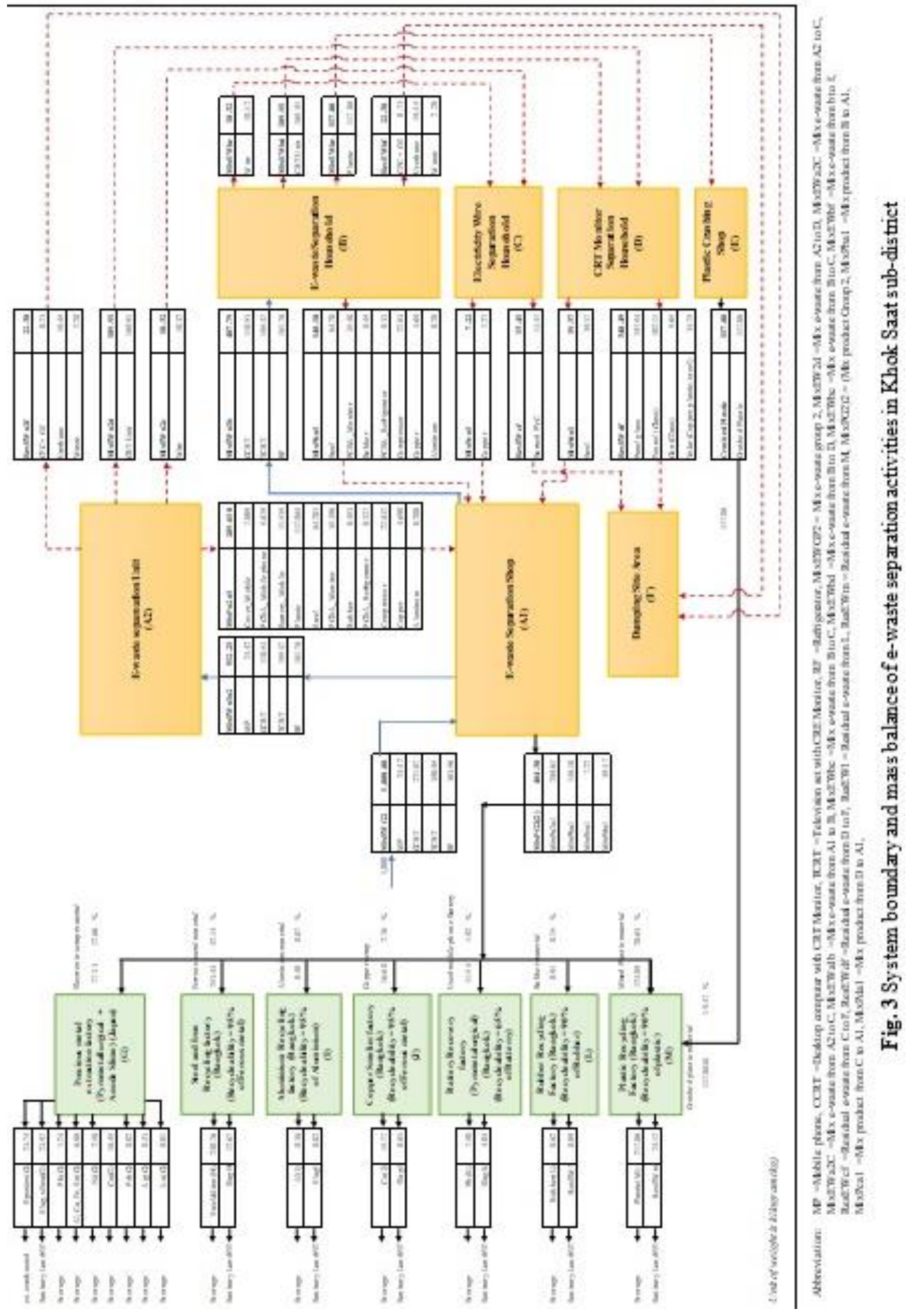




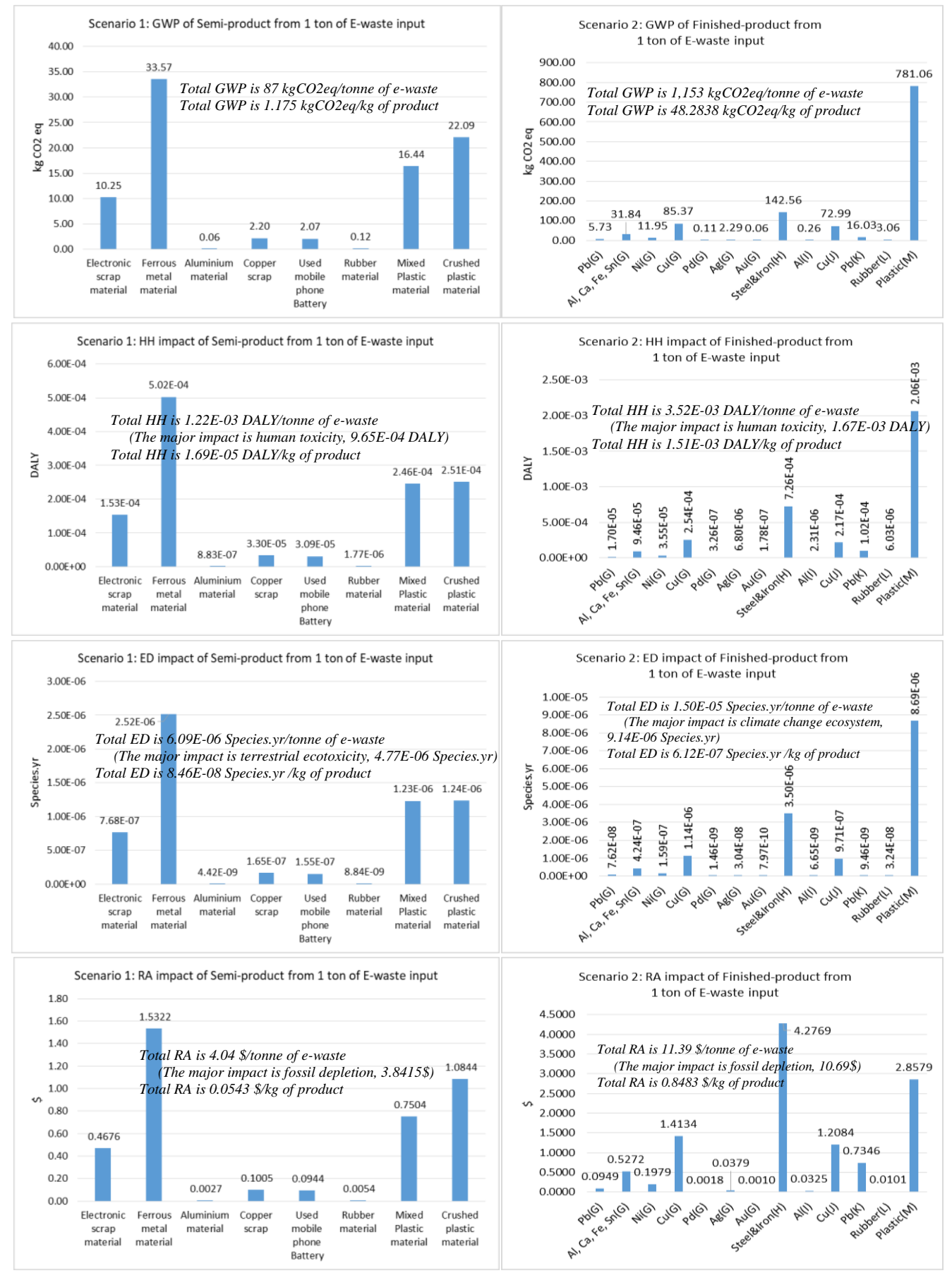

Fig. 4. Environmental and health impact of Product from 1 tone of E-waste at Mid-point Impact 


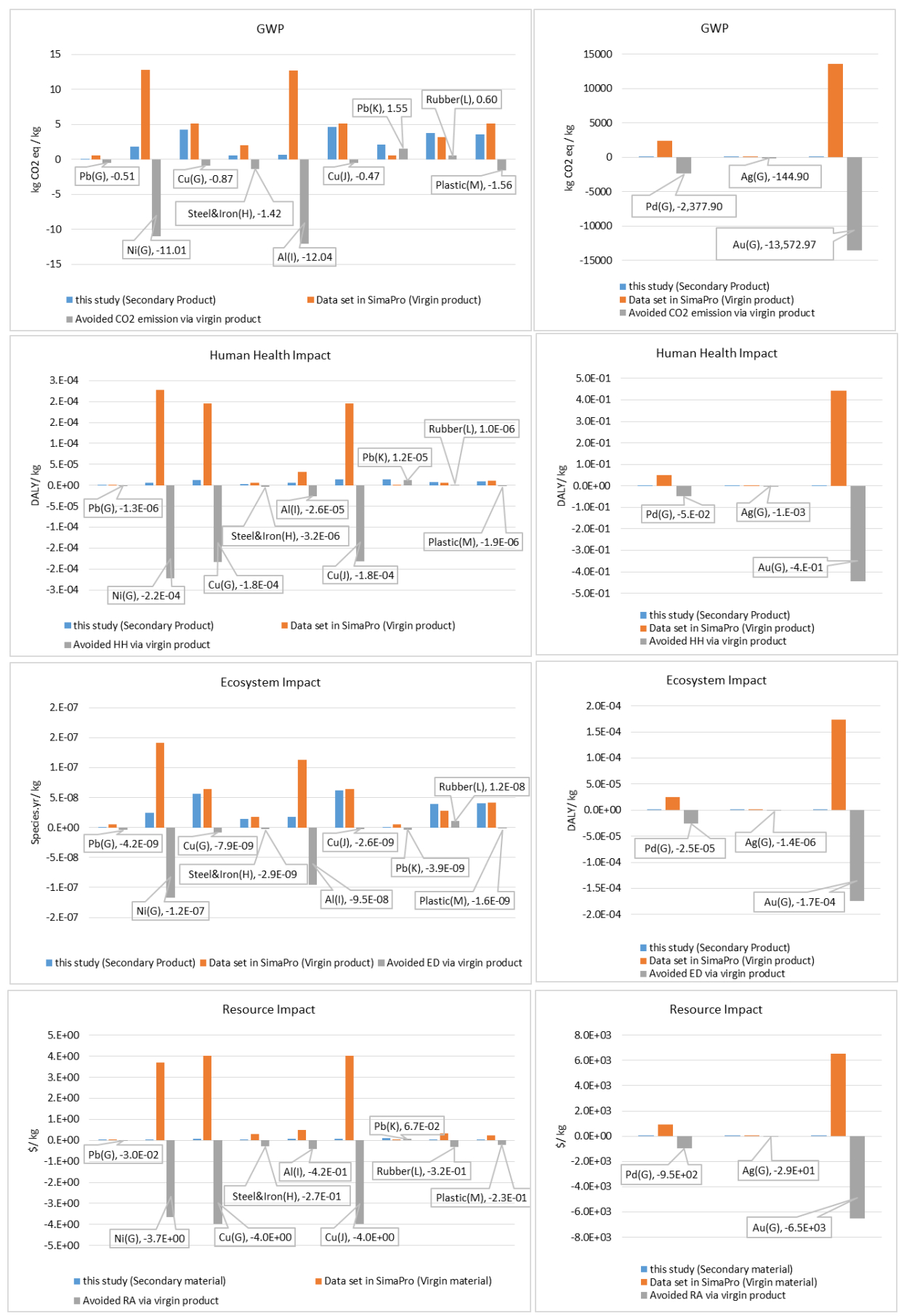

Fig. 5. Co-benefit for recycling as compare to the virgin product 


\section{ACKNOWLEDGEMENTS}

The research budget is supported by Thailand Research Fund through the Royal Golden Jubilee in Ph.D.Program (Grant No.PHD/0118/2553) to Miss Pornnapa Sutawong and Assoc.Prof. Dr. Det Wattanachaiyingcharoen.

\section{R E F E R E N C E S}

Aimin, C., Kim N., D., Xia, H., \& Shuk-mei, H. (2011). Developmental Neurotoxicants in E-waste: An Emerging Health Concern. Environmental Health Perspective, 119(4), 431-438.

Awasthi, A. K., Xianlai, Z., \& Jinhui, L. (2016). Environmental Pollution of electric waste recycling in India: A critical review. Environmnetal Pollution, 211, 259-270.

Department of Disease Control (DDC) (2011) Environmental and health impact and community hazadous waste management study. Bangkok: Ministry of Public Health.

Dwianika, A., Murwaningsari, E., \& Suparta, W. (2020). Analysis of Water Awareness, Accountability, and Governance to improve Sustainability of Firm's Performance in Urban Areas. Geographia Techica, 15(1), 35-42. DOI:10.21163/GT_2020.151.04

Jinglan, H., Wenxiao, S., Yutao, W., Wei , C., \& Xiangzhi, L. (2015). Life cycle assessment of electronic waste treatment. Waste Management, 38, 357-365.

John-Michael, D., \& Yaakov, G. (2015). A model for partnering with the informal e-waste industry: Rationale, Principles and a case study. Resources, Conservation and Recycling, 105, 73-83.

Kabisch S. (2019) Urban Transformations to Pursue Sustainability through Resource Efficiency, Quality of Life and Resilience: A Conceptual Appoach. Geographia Technica, 14, Special issue, 98-107. DOI: 10.21163/GT_2019. 141.23

Patrick, A., \& Roland, H. (2015). Life cycle assessment of post-consumer plastics production from waste electrical and electronic equipment (WEEE) treatment residues in a Central European pastric reycling plant. Science of the Total Environment, 529, 158-167.

Sabrina, O., \& Dabo, G. (2016). China's toxic informal e-waste recycling: local approaches to a global environmental proble. Journal of Cleaner Production, 114, 71-80.

Sadhan Kumar, G., Biswakit, D., Rahul, B., Debashree, D., Jinhui, L., Sannidhya, K. G., . . Andre, N. T. (2016). Waste electical and electronic equipment management and Basel Convention compliance in Bazil, Russia, India, Chiana and South Africa (BRICS) nation. Waste Management \& Research, 34(8), 698-707.

Saetung, P. (2009). The study of participatory impact and management, Community Policy. Bangkok: Asian Institute.

Souza, R. G., Joao C., N. C., Annibal, P. S., Tiago, B. R., Rogerio de, A. B., \& Osvaldo, L. B. (2016). Sustainability assessment and prioritisation of e-waste management option in Brazil. Waste Management, 57, 46-56.

Takashi, F., Hidataka, T., Tetsuro, A., Akifumi, E., Kanae, B., Aya, Y., . . Florencio C., B. J. (2012). Impact of metals in surface matrices from formal and informal electronic-waste recycling around Metro Manila, the Philippines, and intra-Asian comparison. Journal of Hazardous Material, 221-222, 139-146.

Tantanee, S., \& Hantrakul, S. (2019). Municipal waste management challenge of urbanization: Lesson learned from Phitsanulod, Thailand. Geographia Technica, 14, Special issue, 39-46. DOi: 10.21163/GT_2019.141.17

Vi, K. S., \& Matthew, D. (2014). Recycling Mobile Phone Impact on Life Cycle Assessment. Procedia CIRP, 15, 263-271.

Wonorahardjo, S. (2019). Method Development and Surface Utilization: Monitoing Environmental in Urban Society Through Analytical Chemistry. Geographia Technica, 14, Special issue, 8797. DOI: 10.21163/GT_2019.141.22 